\title{
A DIVISÃo dAS BELAS ARTES: KANT E HEGEL
}

\author{
Zilmara de Jesus Viana de Carvalho ${ }^{1}$ \\ Universidade Federal do Maranhão (UFMA) \\ iD https://orcid.org/0000-0003-1991-0250 \\ E-mail: ziljesus@yahoo.com.br \\ Danielton Campos Melonio ${ }^{2}$ \\ Universidade Federal do Maranhão (UFMA) \\ Universidade do Estado do Rio de Janeiro (UERJ) \\ https://orcid.org/0000-0003-1904-4583 \\ E-mail: dasein.da@gmail.com
}

\section{RESUMO:}

O presente artigo aborda numa perspectiva filosófica a relação entre a divisão das artes belas propostas por Kant e Hegel. Objetiva explicitar as aproximações e distanciamentos entre a divisão das belas artes apresentadas pelos filósofos citados, apontando suas semelhanças e diferenças. Fundamenta sua análise nas obras Crítica da Faculdade do Juízo de 1790 e Cursos de Estética de 1820-21, respectivamente elaboradas por Immanuel Kant e Friedrich Hegel. Realiza uma análise comparativa entre a divisão das artes belas kantiana e hegeliana. Apresenta inicialmente a divisão das artes belas na perspectiva kantiana, abordando o conceito de arte bela, sua classificação e sua hierarquia, segundo o filósofo de Königsberg. Em seguida, expõe a divisão das artes segundo Hegel, apresentando o seu conceito de belo artístico, as formas de arte simbólica, clássica e romântica, expondo e analisando também as artes particulares de acordo com o filósofo de Stuttgart. Conclui afirmando que, apesar das diferenças entre ambas análises sobre a divisão das belas artes, tais como a defesa de Hegel em relação belo artístico e a de Kant ao belo natural, a afirmação hegeliana que há uma ciência do belo enquanto a concepção kantiana é de que não há ciência do belo, por exemplo, os filósofos em destaque concordam, entre outros aspectos, que a poesia ocupa o lugar mais alto na hierarquia das belas artes, sendo a mais livre e espiritual delas.

Palavras-Chave: Arte bela; Gênio; Artes particulares; Kant; Hegel.

\section{THE DIVISION OF FINE ARTS: KANT AND HEGEL}

\section{ABSTRACT:}

This article discusses a philosophical perspective the relationship between fine arts Division proposed by Kant and Hegel. Aims to clarify the approaches and distances between the Division of fine arts presented by philosophers, pointing out their similarities and differences. Basing your analysis on The Critic of Judgement of 1790 and Aesthetics Courses (1820-21), respectively prepared by Immanuel Kant and Friedrich Hegel. Performs a comparative analysis between the Division of Kantian and Hegelian fine arts. Features initially the Division of fine arts on Kantian perspective, addressing the concept of beautiful art, your classification and your hierarchy, according to the philosopher of Königsberg. Then, the Division of the arts according to Hegel, introducing the concept of your beautiful, artistic forms of symbolic art, classical and romantic, exposing and analyzing also the private Arts according to the philosopher of Stuttgart. Concludes that, despite the differences between the two analyses on the Division of fine arts, such as the defense of Hegel in beautiful artistic relationship and of Kant to the beautiful natural, the Hegelian claim that there is a science of the beautiful while the Kantian conception is that there is no science of the be it, for example, featured philosophers agree, among other things, that poetry occupies the highest place in the hierarchy of the fine arts, being the more spiritual and free them.

KEYWORDS: Beautiful art; Genius; private Arts; Kant; Hegel.

\footnotetext{
${ }^{1}$ Doutora em Filosofia pela Universidade de São Paulo (USP), São Paulo - SP, Brasil. Professora de Filosofia da Universidade Federal do Maranhão (UFMA), São Luis - MA, Brasil.

${ }^{2}$ Doutorando em Filosofia na Universidade do Estado do Rio de Janeiro (UERJ), Rio de Janeiro - RJ, Brasil. Professor da Universidade Federal do Maranhão (UFMA), Pinheiro - MA, Brasil.
}

CARVALHO, Zilmara de Jesus Viana de; MELONIO, Danielton Campos. A divisão das belas artes: Kant e Hegel. Griot : Revista de Filosofia, Amargosa - BA, v.18, n.2, p.198-216, dezembro, 2018. 


\section{Introdução}

O sistema hegeliano encontra-se com a questão da arte e do belo nas prelações proferidas por Hegel (1770-1831) entre os anos de 1820/21 na universidade de Berlim. Tais aulas ministradas sobre o tema da estética foram compiladas e publicadas postumamente num livro com o título Cursos de Estética (Vorlesungen über die Ästhetik) publicado em 1835.

Dentre os diversos temas apresentados em suas prelações sobre estética, Hegel expõe na parte final da Introdução do seu Curso uma divisão ou classificação das belas artes. Ao apresentar tal divisão Hegel argumenta, fundamentado na lógica do seu sistema filosófico, em favor de uma classificação e hierarquização das belas artes, expondo quais critérios são necessários para estabelecer tal hierarquia.

Por conseguinte, ao dividir as partes de sua Filosofia da bela arte, Hegel propõe também uma divisão das belas artes. No que tange ao critério da relação da ideia com sua configuração Hegel divide as artes em arte simbólica, arte clássica e arte romântica. E ainda subdivide de forma mais específica os tipos de artes chamando-as de artes particulares, que são assim denominadas: arquitetura, escultura, pintura, música e poesia (Hegel, 2001).

Dessa forma, Hegel (2001) apresenta uma divisão das artes que o subsidia a desenvolver sua argumentação sobre a sua Filosofia da arte como ciência do belo artístico. $\mathrm{E}$ ao discorrer sobre as artes simbólica, clássica e romântica e seus desdobramentos particulares (arquitetura, escultura, pintura, música e poesia) permite nos compreender de que maneira a ideia se concretiza no mundo por meio das obras de artes.

Contudo, questiona-se: terá sido Hegel o primeiro a propor uma divisão das artes, apresentando uma classificação das belas artes? Se não, quem o teria precedido, propondo também uma divisão das belas artes antes das preleções feitas pelo filósofo alemão? Se foi proposta uma tal divisão anteriormente, que classificação teria sido apresentada?

As leituras realizadas para a elaboração deste artigo apontaram para o fato de que Immanuel Kant em 1790 (trinta anos antes das prelações de Hegel sobre a estética), já havia apresentado uma divisão das belas artes em seu livro Kritik der Urteilskraft, o que nos permite supor que as divisões das belas artes propostas por Kant e Hegel podem guardar afinidades, apesar de possíveis diferenças.

Assim, o objetivo deste artigo é explicitar as afinidades e os distanciamentos entre a divisão das belas artes apresentadas por Kant e Hegel na Crítica da Faculdade de Julgar e no Cursos de Estética, respectivamente.

Para efetivar tal objetivo será adotado o seguinte roteiro. Em primeiro lugar, apresentar-se-á a divisão das belas artes segundo os critérios definidos por Kant na Crítica da Faculdade do Juízo. Para tal empresa, será discutido o conceito de bela arte, a divisão propriamente dita das belas artes e a comparação que o filósofo de Königsberg faz entre as belas artes, assim como a sua hierarquização.

Em seguida, será exposta a divisão das belas artes, conforme os critérios fornecidos por Hegel em seu Curso de Estética e, ainda de acordo com este, o conceito de bela arte, apresentadas as distinções entre arte simbólica, arte clássica e arte romântica, caracterizando as artes particulares, e discutindo, por fim, a hierarquia entre as belas artes.

Como epílogo deste artigo será realizada uma análise comparativa com intuito de expor as aproximações e os distanciamentos entre as propostas de divisão das belas artes manifestadas por ambos os filósofos alemães.

CARVALHO, Zilmara de Jesus Viana de; MELONIO, Danielton Campos. A divisão das belas artes: Kant e Hegel. Griot 


\section{Arte bela e divisão das belas artes em Kant}

Dentre os diversos problemas filosóficos levantados e debatidos no séc. XVIII (tais como a questão da natureza, do conhecimento, da religião, da história, do direito, do Estado e da sociedade) a questão estética foi de grande relevância para os filósofos da época (CASSIRER, 1997). Discutiu-se se o belo deve ser julgado a partir de aspectos exteriores objetivos da obra de arte, permitindo uma regra geral para a produção e julgamento do belo, ou se o belo é experimentado subjetivamente pelos sujeitos, sem depender da própria obra de arte. Os partidários da primeira tese abordaram o problema a partir da questão da estética clássica e da objetividade do belo; os segundos defenderam a questão da subjetividade do belo e o problema do gosto (CASSIRER, 1997, p. 371- 411).

No bojo deste debate Immanuel Kant (1724-1804) analisa a questão da estética por uma perspectiva própria, apontando que a questão do belo não deve ser compreendida pelo viés da pura objetividade ou do simples subjetivismo. A questão do belo deve ser entendida por uma perspectiva da Filosofia Transcendental, focando no que ocorre com o sujeito que experimenta o belo e não buscando compreender exatamente como se produz a obra ou se ela carrega consigo a beleza, de forma objetiva.

Com efeito, o belo não é uma característica objetiva da obra de arte, uma vez que é sentido pelo sujeito que o experimenta, não, contudo, como mera experimentação de sensações, mas como acordo da relação entre as faculdades da imaginação e do entendimento no momento do julgamento de experiências estéticas belas.

$O$ acordo entre imaginação e entendimento produz um indicativo para o sujeito que experimenta autenticamente o belo (não como sensações agradáveis ou como acordo conceituais), fazendo-o sentir prazer em face de tal experiência estética singular. Diante de uma experiência estética do belo o sujeito que julga autenticamente só pode produzir necessariamente o seguinte juízo: "Isto é belo", e querer comunicar universalmente sua experiência, passível de ser experimentada também por outros que tem a mesma estrutura formada pelas faculdades da imaginação, entendimento e razão.

Assim, Kant apresenta uma perspectiva própria para analisar a questão do belo e, por conseguinte, seus desdobramentos, como a questão da arte, por exemplo. Nesse sentido, o filósofo de Königsberg não se ocupa necessariamente com a arte como obra objetiva, mas com o que permite ajuizá-la com gosto, ou seja, a sua concepção do belo repercute em sua visão sobre a arte fazendo-o defender que o que importa é compreender como se julga a experiência do belo e como a arte poder provocar isso nos sujeitos.

Portanto, a arte como obra não é o foco da análise empreendida por Kant, mas o sujeito que a ajuíza e o gênio que permite ao artista provocar nos sujeitos tal experiência autêntica do belo.

Pelo exposto, cabe ressaltar que a abordagem kantiana do belo e da arte será o pano de fundo da análise ora exposta sobre a divisão das artes belas em Kant. Para tanto será apresentada a seguinte análise com o fito de permitir atingir o objetivo analítico proposto neste artigo. Dessa forma, para o desenvolvimento desta seção será inicialmente apresentado o conceito de arte em Kant, para posteriormente analisar o que significa arte bela, para, por fim, expor a divisão e hierarquização das artes belas.

Antes, porém, de se apresentar a divisão das belas artes proposta por Kant faz-se necessário inicialmente expor o seu conceito de arte. Para este intuito será apresentado o conceito de arte em geral e de bela arte.

CARVALHO, Zilmara de Jesus Viana de; MELONIO, Danielton Campos. A divisão das belas artes: Kant e Hegel. Griot 
No sentido de conceituar arte Kant faz algumas distinções necessárias. Primeiramente afirma que a arte se difere da natureza, assim como o "fazer (facere) distingue-se do agir ou atuar em geral (agere) e o produto ou a consequência da primeira enquanto obra (opus), distingue-se da última como efeito (effectus)." (KANT, 1995, p. 149).

Só é possível, segundo Kant, denominar arte a produção realizada de forma livre e racional. Mesmo que se realizem "obras" na natureza, como o exemplo das abelhas que constroem suas colmeias, como se parecessem obra de arte, tais seres, contudo, não o fazem de maneira racional e livre (KANT, 1995). Assim, uma obra de arte autêntica é resultante da ação livre e racional dos seres humanos e não uma mera ação mecânica e sem sentido. A arte pressupõe, portanto, liberdade e racionalidade, eis o que Kant (1995) afirma.

Além de se distinguir da natureza, a arte também se difere da ciência, pois "[...] somente pertence à arte aquilo que, embora o conheçamos da maneira mais completa, nem por isso possuímos imediatamente a habilidade para fazê-lo." (KANT, 1995, p. 149). Com efeito, ter conhecimento sobre um conteúdo ou assunto e poder realizar descrições sobre como funciona uma máquina, por exemplo, não significa que se saiba construir tal máquina. Assim, a arte exige a habilidade humana de produzir a obra de arte e não somente ter conhecimento sobre esta, sendo capaz de descrevê-la teoricamente (KANT, 1995).

Ao estabelecer a distinção entre arte remunerada e arte livre o filósofo de Königsberg diferencia a arte do mero ofício. Enquanto aquela arte é considerada como trabalho devido ao seu caráter penoso e remuneratório, sendo realizada de forma impositiva, a arte livre é uma "ocupação que é agradável por si própria", resultando de um jogo livre e não de uma obrigação impositiva, como um trabalho (KANT, 1995, p. 150). Desse modo, quem produz obras resultante do trabalho remunerado e limitado a regras, de forma penosa e sem liberdade, não poder ser considerado um artista e sua obra não poderá ser avaliada como arte, pois arte é diferente de ofício, observa Kant (1995, p. 149).

Portanto, a arte não pode ser confundida com as obras da natureza, com a ciência (capacidade teórica de conhecer e descrever fenômenos), tampouco com os ofícios (trabalho remunerado).

No sentido de definir o que significa arte bela (Schöne Kunst) Kant observa inicialmente que não "[...] há uma ciência do belo, mas somente crítica, nem uma ciência bela, mas somente arte bela." (KANT, 1995, p. 150). Dito de outra maneira, não é possível realizar uma análise científica da arte bela, pois não seria possível expor por argumentos científicos se "[...] algo deve ser tido por belo ou não", uma vez que "[...] se o juízo sobre a beleza pertencesse à ciência, ele não seria nenhum juízo do gosto." (KANT, 1995, p. 150).

Segundo o filósofo de Königsberg o que possivelmente teria ocasionado o equívoco comum de se pensar que seria possível uma ciência bela:

[...] não foi sem dúvida outra coisa que o ter-se observado bem corretamente que para a arte bela em sua inteira perfeição requer-se ciência, como por exemplo o conhecimento de línguas antigas, conhecimento literário de autores que são considerados clássicos, história, conhecimento de antigüidade etc., e por isso estas ciências históricas, pelo fato de constituírem a preparação necessária e a base para a arte bela, em parte também porque nelas foi compreendido mesmo o conhecimento dos produtos da arte bela (oratória e poesia), foram um equívoco terminológico chamadas ciências belas (KANT, 1995, p. 151).

Nesse sentido, por se entender comumente que para ter acesso às artes belas seria necessário adquirir conhecimentos e fundamentos das "ciências históricas", tornando-se as-

CARVALHO, Zilmara de Jesus Viana de; MELONIO, Danielton Campos. A divisão das belas artes: Kant e Hegel. Griot 
sim mais erudito, confundiu-se dessa maneira a crítica da arte com a arte bela, tentando-se afirmar que existiria uma ciência bela. Não há ciência do belo, mas apenas crítica do belo, observa Kant (1995, p. 151).

É necessário também distinguir a arte mecânica (mechanische Kunst) da arte estética (ästhetische Kunst). A primeira executa ações para tornar um objeto efetivo, enquanto a segunda "[...] tem por intenção imediata o sentimento de prazer [...]" (KANT, 1995, p. 151).

Por seu turno a arte estética pode ser dividida em dois tipos, a saber, arte agradável ou arte bela. Esta última é "[...] um modo de representação que é por si própria conforme a fins e, embora sem fim, todavia promove a cultura das faculdades do ânimo para a comunicação em sociedade." (KANT, 1995, p. 151). De outra forma, a arte agradável é aquela que tem "[...] em vista simplesmente o gozo [...]", sem nenhuma preocupação com a reflexão, pois deve promover apenas o entretenimento, e são desse tipo "[...] todos os jogos que não comportam nenhum interesse, afora o de deixar passar imperceptivelmente o tempo" (KANT, 1995, p. 151).

Ademais, a arte é agradável "[...] se o seu fim é que o prazer acompanhe as representações enquanto simples sensações [...]", e a arte é bela "[...] se seu fim é que o prazer as acompanhe enquanto modos de conhecimento." (KANT, 1995, p. 151). Com efeito, a arte estética é "[...] uma arte que tem por padrão de medida a faculdade de juízo reflexiva e não a sensação sensorial [...]", ou seja, a arte estética permite comunicar o "prazer da reflexão" e não somente o "prazer do gozo" das meras sensações.

Outro aspecto destacado por Kant sobre a arte bela é que ela deva parecer que é natureza mesmo que seja produto da arte, isto é, da ação livre e racional do ser humano. Em outros termos, a natureza "[...] era bela se ao mesmo tempo parecia ser arte; e a arte somente pode ser denominada bela se temos consciência de que ela é arte e de ela apesar disso nos parece ser natureza." (KANT, 1995, p. 152).

Fundamentado nessa assertiva, o filósofo intenta demonstrar que:

[...] embora a conformidade a fins no produto da arte bela na verdade seja intencional, ela contudo não tem que parecer intencional; isto é, a arte bela tem que passar por natureza, conquanto a gente na verdade tenha consciência dela como arte. Um produto da arte, porém, aparece como natureza pelo fato de que na verdade foi encontrada toda a exatidão no acordo com regras segundo a quais, unicamente, o produto pode tornar-se aquilo que ele deve ser, mas sem esforço, sem que transpareça a forma acadêmica, isto é, sem mostrar um vestígio de que a regra tenha estado diante dos olhos do artista e tenha algemado as faculdades de seu ânimo (KANT, 1995, p. 152).

Dessa forma, segundo Kant, a autêntica obra de arte tem que parecer como se fosse obra da natureza, ou seja, a perfeição da natureza deve se apresentar na obra sem que pareça que foi realizada com esforço intencional do artista, mediante regras do fazer artístico. As regras que orientaram o artista e a sua intenção devem ser diluídas na obra de arte a tal ponto que pareça que ela é um produto da própria natureza, mesmo que se saiba que é uma obra artística, e, portanto, obra humana. 
E para que a obra de arte possa se passar por natureza é necessário que a arte bela seja produzida pelo gênio (das Genie). Segundo o filósofo de Königsberg, o gênio "[...] é o talento (dom natural) [Naturgabe] que dá a regra à arte $[. .]$.$" , ou seja, “[...] é a disposição$ inata do ânimo (ingenium) pela qual a natureza dá a regra à arte." (KANT, 1995, p. 153).

Dito de outra forma, o gênio é a faculdade natural do artista de criar suas próprias regras do fazer e da expressão artística. Enquanto muitos necessitam ser guiados, treinados e educados para produzir arte mediante regras previamente definidas, o gênio, devido a sua originalidade e talento singulares cria as suas próprias regras e as torna exemplares sem que ensine diretamente isso aos outros. $O$ gênio expõe suas regras sub-reptícias na própria obra de arte sem esforço, parecendo que a obra é produto da própria natureza e não da arte. Se quisermos encontrar as regras criadas pelo gênio devemos buscá-las na própria obra e não nos ensinamentos dele, pois o mesmo não é capaz de descrever em argumentos e conceitos o seu fazer artístico (KANT, 1995).

Portanto, a arte bela segundo Kant não é ciência, é estética, e tem que se passar por natureza mesmo sendo arte e deve ser expressa pelo gênio - que é capaz de produzir as obras de arte mediante as regras criadas por ele próprio, fazendo parecer, de forma original e com talento singular, que a obra de arte é natureza.

Tendo em vista o exposto acerca dos conceitos de arte e de arte bela em Kant, faz-se necessário apresentar propriamente a divisão das artes belas e suas classificação hierárquica.

Na Crítica da Faculdade do Juízo, de 1790, Kant, no bojo da análise sobre a questão do belo e do sublime, apresenta também uma divisão (Einteilung), organização ou classificação das belas artes, dividindo-as e organizando-as segundo critérios racionais.

Segundo este, no intuito de definir um critério para dividir as belas artes,

[...] não podemos, pelo menos como tentativa, escolher para isso nenhum princípio mais cômodo que o da analogia da arte como o modo de expressão de que os homens se servem no falar para comunicarem-se entre si tão perfeitamente quanto possível, isto é, não simplesmente segundo conceitos mas também segundo suas sensações. Este modo de expressão consiste na palavra, no gesto e no som (articulação, gesticulação e modulação). Somente a ligação destes três modos de expressão constituem a comunicação completa do falante. Pois pensamento, intuição e sensação são assim simultâneas e unificadamente transmitidos aos outros (KANT, 1995, p. 165-166).

Com efeito, o critério kantiano para dividir e classificar as belas artes são os modos que os humanos se utilizam para se comunicar entre si, isto é, por meio da fala, do gesto e do som, o que os possibilita transmitir aos demais seus pensamentos, intuições e sensações. Assim, os tipos de belas artes são aqueles que permitem comunicar entre os humanos através da expressão da palavra, do gesto e do som.

Nesse sentido, Kant apresenta a classificação geral das belas artes em três grandes tipos, a saber, artes elocutivas, artes figurativas e artes do jogo das sensações, que serão analisadas a seguir.

${ }^{3} \mathrm{O}$ foco deste artigo não é analisar o conceito de gênio em Kant, contudo foi necessário fazer menção a ele, mesmo que brevemente, para relacioná-lo com a arte bela. Para aprofundamento da leitura e compreensão da categoria gênio cf. KANT. Crítica da Faculdade do Juizo, do $\$ 46$ ao $§ 50$.

CARVALHO, Zilmara de Jesus Viana de; MELONIO, Danielton Campos. A divisão das belas artes: Kant e Hegel. Griot 
As artes elocutivas, de acordo com Kant, são a eloquência (Beredsamkeit) e a poesia (Dichtkusnt). A primeira é “[...] a arte de exercer um ofício do entendimento como um jogo livre da faculdade da imaginação [...]", enquanto a poesia é “[...] a arte de executar um jogo livre da faculdade da imaginação como ofício do entendimento." (KANT, 1995, p. 166)

Dessa forma, enquanto um orador "[...] anuncia um ofício e executa-o como se fosse simplesmente um jogo com idéias para entreter os ouvintes", o poeta, por sua vez, "[...] simplesmente anuncia um jogo que entretém com idéias e do qual contudo se manifesta tanta coisa para o entendimento, como se ele tivesse simplesmente tido a intenção de impulsionar o seu ofício." (KANT, 1995, p. 156).

Dito de outra forma,

[...] o orador na verdade dá algo que ele não promete, a saber, um jogo que entretém a faculdade da imaginação; mas ele também deixa de cumprir algo que ele promete e que é, pois, seu anunciado ofício, a saber, ocupar o entendimento conforme a um fim. O poeta, ao contrário, promete pouco e anuncia um simples jogo com idéias, porém realiza algo que é digno de um ofício, ou seja, proporcionar ludicamente alimento para o entendimento e mediante a faculdade da imaginação dar vida a seus conceitos; por conseguinte aquele no fundo realiza menos e este mais do que promete (KANT, 1995, p. 167).

Assim, tanto a eloquência quanto a poesia são artes elocutivas, expressando-se por meio da palavra e da fala, contudo distinguem-se mutuamente na medida em que a poesia é mais livre que a eloquência, pois o poeta se deixa levar mais pela faculdade da imaginação, proporcionando ao ouvinte ou ao leitor um prazer estético diante das palavras que profere, enquanto a eloquência, mesmo prometendo ser um livre jogo de palavras, não deixa de ser um oficio, com um fim a ser alcançado no discurso. O poeta, por sua vez, está livre de cumprir este fim, é livre para promover o livre jogo da imaginação com o entendimento por meio das palavras.

Além das artes elocutivas há também as artes figurativas, que diferem daquelas na medida em que se dirigem às aparências dos sentidos e não às palavras, isto é, são expostas por meio das imagens.

O primeiro tipo de arte figurativa é a plástica (Plastik) enquanto a segunda é a pintura (Malerei). Segundo Kant, os dois tipos "[...] formam figuras no espaço, para a expressão por idéias; aquela [a plástica] dá a conhecer figuras por dois sentidos, a vista e o tato (embora não com vistas à beleza); a segunda [a pintura] somente pela primeira." (KANT, 1995, p. 167). Com efeito, as artes figurativas produzem obra de arte que se apresentam no espaço, sendo que a plástica permite ser apreciada tanto pela visão como pelo tato, enquanto que a pintura somente pode ser apreciada pela visão.

Dentre as artes figurativas do tipo plástica estão a escultura (Bildhauerkunst) e a arquitetura (Baukunst). A escultura "[...] é aquela que apresenta corporalmente conceitos de coisas como elas poderiam existir na natureza [...]". A arquitetura, por seu turno, “[...] é a arte de apresentar conceitos de coisas que somente pela arte são possíveis e cuja forma, não tem como fundamento determinante a natureza mas um fim arbitrário, com este propósito contudo ao mesmo tempo estético conforme a fins." (KANT, 1995, p. 167).

Para ilustrar tal diferenciação entre escultura e arquitetura, Kant se vale do seguinte exemplo:

CARVALHO, Zilmara de Jesus Viana de; MELONIO, Danielton Campos. A divisão das belas artes: Kant e Hegel. Griot 


\begin{abstract}
Assim estátuas de homens, de deuses, de animais, etc. são da primeira espécie; mas templos ou edifícios suntuosos para fins de assembleias públicas, ou também casas, arcos honoríficos, colunas, mausoléus etc., erigidos como monumentos comemorativos, pertencem à arquitetura. (KANT, 1995, p. 167-168).
\end{abstract}

Por conseguinte, artes figurativas plásticas do tipo escultura e arquitetura têm o objetivo de apresentar no espaço ideias estéticas por meio de estátuas (escultura) e de construções (arquitetura) com caráter não exatamente utilitário como, por exemplo, os templos ou monumentos erguidos para fins comemorativos ou religiosos. Assim, tanto as estátuas quanto os edifícios com caráter não exatamente imobiliário são produtos das artes figurativas plásticas.

Ademais, Kant observa que "certos produtos, dos quais se esperaria que devessem pelo menos em parte mostrar-se como arte bela, que eles são sem espírito, embora no que concerne ao gosto não encontre nada de censurável" (KANT, 1995, p. 158-159). Ou seja, algumas obras de bela arte não têm espírito e por isso não permitem a vivificação do ânimo do ajuizador, apesar de permitir o ajuizamento do belo, já que o espírito, no sentido estético de acordo com a abordagem kantiana, "significa o princípio vivificante no ânimo." E segundo Kant este princípio é a "[...] faculdade da apresentação de ideias estéticas [...]" (KANT, 1995, p. 159).

Com efeito, Kant define ideia estética como se segue:

[...] por uma idéia estética entendo, porém, aquela representação da faculdade da imaginação que dá muito a pensar, sem que contudo qualquer pensamento determinado, isto é, conceito, possa ser-lhe adequado, que consequentemente nenhuma linguagem alcança inteiramente nem pode tornar compreensível. Vê-se facilmente que ela é a contrapartida [...] de uma idéia da razão, que inversamente é um conceito ao qual nenhuma intuição (representação da faculdade da imaginação) pode ser adequada. (KANT, 1995, p. 159).

Além disso, é necessário observar que:

Tais representações da faculdade da imaginação podem chamar-se idéias, em parte porque elas pelo menos aspiram algo situado acima dos limites da experiência, e assim procuram aproximar-se de uma representação dos conceitos da razão (das idéias intelectuais), o que dá a aparência de uma realidade objetiva; por outro lado, e na verdade principalmente por que nenhum conceito pode ser plenamente adequado a elas enquanto intuições internas (KANT, 1995, p. 159).

Assim, por meio das ideias estéticas a faculdade da imaginação apresenta representações que podem ser denominadas de ideias porque aspiram alcançar algo para além dos limites da experiência, contudo não são propriamente ideias da razão, pois não produzem conceitos. As ideias estéticas possibilitam vivificar o ânimo, dando espírito à obra de arte.

Retomando a classificação das belas artes, a segunda classe de artes figurativas, de acordo com Kant, é a arte pictórica (Malerkunst), que pode ser definida como uma "[...] espécie de arte figurativa que apresenta a aparência sensivel como artisticamente ligada a idéias" (KANT, 1995, p. 168), ou seja, apresenta as ideias estéticas através da aparência sensível. As formas de apresentação da arte pictórica são: a pintura (Malerei) e a jardinagem ornamental (Lustgärtnerei) (KANT, 1995).

Sobre a pintura Kant declara inicialmente que "[...] dá só a aparência da extensão corporal", enquanto a jardinagem ornamental "[...] a dá de acordo com a verdade, mas dá

CARVALHO, Zilmara de Jesus Viana de; MELONIO, Danielton Campos. A divisão das belas artes: Kant e Hegel. Griot 
somente a aparência de utilização e uso para outros fins, enquanto simplesmente destinada ao jogo da imaginação na contemplação de suas formas." (KANT, 1995, p. 168). Dito de outra forma, a pintura se expressa apenas para a visão, através de figuras, desenhos e cores, enquanto que a jardinagem ornamental além de se apresentar para a visão tem também um certo caráter utilitário, decorativo.

Além disso, cabe observar que a jardinagem ornamental:

[...] não é outra coisa que a decoração do solo com a mesma variedade (relvas, flores, arbustos e árvores, mesmo riachos, colinas e vales) com que a natureza expõeno ao olhar somente composta de modo diverso e conformemente a certas idéias. (KANT, 1995, p. 168).

Quanto à pintura, acrescenta Kant (1995, p. 169):

[...] em sentido amplo, eu incluiria ainda a ornamentação dos aposentos com tapeçarias, adereços e todo belo mobiliário, que serve só para a vista; do mesmo modo, a arte da indumentária segundo o gosto (anéis, tabaqueiras etc.). Pois um canteiro com toda espécie de flores, um aposento com toda espécie de adornos [...], constituem uma festa suntuosa uma espécie de pintura que, como as propriamente assim chamadas (que por assim dizer não têm a intenção de ensinar história ou conhecimento da natureza), está aí simplesmente para ser vista, para entreter a faculdade da imaginação no jogo livre com as idéias e ocupar a faculdade de juízo estética sem um fim determinado.

Como se percebe, Kant amplia o conceito e exemplos do que seria uma pintura, alargando para tudo aquilo que seja obra humana que tenha o objetivo estético de entreter a faculdade da imaginação por meio da vista. Dessa forma, tanto um quarto decorado quanto um jardim ornamentado ${ }^{4}$, assim como roupas e indumentários com fins apenas de ser apreciado pela visão sem caráter utilitário são considerados pelo filósofo de Königsberg como formas de apresentação de pinturas.

O terceiro e último gênero de arte bela segundo Kant é a arte do belo jogo das sensações (Kunst des schönen Spiels der Empfindungen). Este tipo de arte é expresso por meio das sensações, sem ter o caráter meramente sensorial (sensações agradáveis), dirigidos ao ouvido e a vista. Os tipos de arte desse gênero são: música (Musik) e arte das cores (Farbenkunst).

Apesar deste tipo de arte bela ser vinculada às sensações, Kant faz questão de observar que não se deve entender que sejam ligadas a meras sensações agradáveis:

[...] não se pode dizer com certeza se uma cor ou um tom (som) são simplesmente sensações agradáveis, ou se já se trata em si de um jogo belo de sensações e se, como tal, comporta um ajuizamento estético, uma complacência na forma (KANT, 1995, p. 170).

\footnotetext{
${ }^{4}$ Fiona Hughes discute o potencial estético político de um jardim ornamentado em “Um potencial político no juízo estético reflexionante: Kant, Hannah Arendt e “Pequena esparta, de Ian Hamilton Finlay" trans. Giorgia Cecchinato In Gosto, interpretação e crítica, Vol.1, ed. by Verlaine Freitas, Rodrigo Duarte, Giorgia Cecchinato, Cíntia Vieira da Silva, Belo Horizonte, Relicário 2014.
}

CARVALHO, Zilmara de Jesus Viana de; MELONIO, Danielton Campos. A divisão das belas artes: Kant e Hegel. Griot 
Ou seja, para que se possa ajuizar como estético as sensações produzidas pela música direcionada ao ouvido e a arte das cores a visão não se pode percebê-las apenas como sensações agradáveis, pois assim não poderiam ser consideradas estéticas.

Contudo, durante a execução de uma peça musical se se percebe o caráter matemático e estrutural da música (percebendo a divisão do tempo, a composição dos compassos, a estrutura das escalas musicais etc.) compreende-se que não se tratam de meras sensações, mas de um jogo livre das sensações, direcionadas à faculdade da imaginação em sua atividade estética.

Com efeito, se se compreender tal jogo das sensações dessa maneira e não como sensações meramente agradáveis (não passíveis de comunicação universal), então "[...] poderíamos ver-nos coagidos a não considerar as sensações [...] como simples impressão dos sentidos, mas como efeito de um ajuizamento da forma no jogo de muitas sensações." (KANT, 1995, p. 170). Assim, a música e a arte das cores não podem ser tidas como meras expressões de sensações agradáveis, pois assim não poderiam ser classificadas como arte bela, eis o que observa Kant (1995).

Além da classificação por ora apresentada das artes belas, o filósofo de Königsberg também expõe uma combinação das diversas belas artes com intuito de demonstrar que tal combinação pode produzir outras formas de expressão artísticas, ampliando a capacidade de manifestação de ideias estéticas através da arte bela.

Sobre isto Kant (1995, p. 170) declara que:

\begin{abstract}
A eloquência pode ligar-se a uma apresentação pictórica de seus sujeitos também como objetos em um espetáculo; a poesia pode ligar-se à musica no canto; este, porém, ao mesmo tempo à apresentação pictórica (teatral) em uma ópera; o jogo das sensações em uma música pode ligar-se ao jogo das figuras na dança etc. Também a apresentação do sublime, na medida em que pertence à arte bela, pode unificarse com a beleza em uma tragédia rimada, em um poema didático, em um oratório; $\mathrm{e}$ nessas ligações a arte bela é ainda mais artística [...].
\end{abstract}

Dessa forma, a ligação de uma arte bela com outra produz uma terceira. O teatro é a combinação da eloquência com a arte pictórica (palavras, cenário etc.). O canto é a combinação da poesia com a música (letra, melodia e harmonia). A ópera combina música e arte pictórica. E a dança, por sua vez, é a conjunção da música com os gestos.

Portanto, a apresentação de ideias estéticas encontra várias formas de expressão artísticas que possam manifestá-las, sejam elas artes belas dos três grandes gêneros, a saber, elocutivas, figurativas ou jogo livre das sensações, ou em suas combinações que produzem outras formas de manifestação artísticas como a dança, o teatro, etc.

Além da classificação das artes belas exposta por Kant na Kritik der Urteilskaft, este expõe também uma hierarquia entre elas. Segunda tal hierarquia, a poesia ocupa o lugar mais alto nesta escala classificatória. De acordo com Kant (1995, p. 171):

[entre] todas as artes a poesia (que deve sua origem quase totalmente ao gênio e é a que menos quer ser guiada por prescrição ou exemplos) ocupa a posição mais alta. Ela alarga o ânimo pelo fato de ela pôr em liberdade a faculdade da imaginação e de oferecer dentre dos limites de um conceito dado sob a multiplicidade ilimitada de formas possíveis concordantes com ele, aquela que conecta a sua apresentação com uma profusão de pensamentos, à qual nenhuma expressão linguística é inteiramente adequada, e, portanto, elevar-se esteticamente a idéias. Ela fortalece o ânimo enquanto permite sua faculdade livre, espontânea e indepen-

CARVALHO, Zilmara de Jesus Viana de; MELONIO, Danielton Campos. A divisão das belas artes: Kant e Hegel. Griot 
dente da determinação da natureza, para contemplar e ajuizar a natureza como fenômeno segundo pontos de vista que ela não oferece por si na experiência nem ao sentido nem ao entendimento, e, portanto, para utilizá-la em vista e por assim dizer como esquema do supra-sensível.

Com efeito, a poesia é a mais elevada das artes belas, pois é a mais livre, a que permite de forma mais efetiva a apresentação de ideias estéticas, apresentando a natureza de tal forma que nos eleve ao suprassensível. A poesia é, assim, a mais elevada das belas artes, segundo Kant (1995).

Em segundo lugar, depois da poesia, Kant classifica a arte do som (Tonkunst) ou a música como a segunda arte mais elevada, considerando-se o critério da importância do movimento do ânimo. Ele observa que, embora tal arte " [...] fale por meras sensações sem conceitos, por conseguinte não deixa como a poesia sobrar algo para a reflexão, ela contudo move o ânimo de modo mais variado e, embora só passageiro, no entanto mais íntimo" (KANT, 1995, p. 173).

Dessa forma, a música possibilita movimentar o ânimo, mesmo que não produza material para a razão, produzindo com seus sons (melodia e harmonia) uma linguagem dos afetos, plenamente comunicável (KANT, 1995). É nesse sentido que a arte do som ocupa um lugar abaixo da poesia na hierarquia proposta por Kant, pois movimenta o ânimo de forma distinta de como a poesia realiza esse movimento do ânimo.

Todavia, Kant observa que a música é "mais gozo que cultura" (KANT, 1995, p. 173), produzindo mais fruição do que propriamente cultura, assim como faz a poesia. E se tomarmos como critério o alargamento das faculdades (tornando-os mais racionais e propensos a ideias estéticas) que as artes belas podem proporcionar, então a música "[...] possui entre as belas artes o último lugar [...] porque joga simplesmente com sensações." (KANT, 1995, p. 174). Nesse sentido, a partir deste segundo critério a música deixa de ser a segunda na hierarquia das artes belas e passa a ser a última.

Ademais, nesse diapasão, o filósofo de Königsberg declara:

[...] é inerente à musica uma certa falta de urbanidade, pelo fato de que, principalmente de acordo com a natureza dos instrumentos, ela estende a sua influência além do que se pretende dela (à vizinhança) e assim como que se impõe, por conseguinte causa dano a liberdade dos outros, estranhos à sociedade musical (KANT, 1995, p. 175).

Assim, a música, devido à sua forma de propagação por meio de sons que transitam no ar, não é tão polida e educada como a pintura, por exemplo. Os sons dos instrumentos, mesmo que não se queira, acabam chegando também aos ouvidos daqueles que não gostariam de ouvir tais melodias, ritmos e harmonias. Mesmo que esteja em um ambiente fechado, a música tem a capacidade de ultrapassar os limites físicos desse espaço e atingir tanto àqueles que gostariam de ouvi-la, quanto àqueles que não desejariam apreciá-la, eis uma característica da música que Kant critica, e por isso a rebaixa na hierarquia das belas artes.

Por outro lado, as artes figurativas não têm esse caráter de falta de urbanidade descrita pelo filósofo, pois se deve "[...] apenas desviar os olhos quando não quer admitir sua influência" (KANT, 1995, p. 1175). Ou seja, quando não se quer apreciar uma pintura, um desenho ou escultura deve-se apenas deixar de dirigir a vista para a apreciação de tais obras, o que não pode acontecer exatamente com a música quando, por exemplo, o som de 
um violino de alguém que pratica dentro de uma casa invade os demais cômodos sem que se possa evitar que isto ocorra.

Rebaixada a música na hierarquia das artes belas, de acordo com o critério das meras sensações, as artes figurativas se aproximam da poesia, que permanece no topo da escala hierárquica kantiana das belas artes.

E dentre as artes figurativas a pintura é a mais elevada, pois:

Entre as artes figurativas, eu daria preferência à pintura, em parte porque, como a arte do desenho, base de todas as demais artes figurativas, em parte porque ela pode adentrar-se muito mais na região das idéias e também pode estender, de acordo com estas, o campo da intuição mais do que é permitido às demais (KANT, 1995, p. 175).

Com efeito, a pintura pode expressar mais ideias estéticas que as demais artes figurativas como a escultura, arquitetura e a jardinagem ornamental, uma vez que está mais próxima do campo da razão do que as demais artes que se vinculam à visão e as do belo jogo das sensações, como a música e arte das cores.

Pelo que foi exposto até o momento, foi possível apresentar a divisão que Kant propõe das artes belas, compreendendo inicialmente o que significa arte em geral e arte bela, para, por fim, expor a classificação kantiana. Segundo o filósofo de Königsberg, as artes belas se dividem em elocutivas (eloquência e poesia), figurativas (escultura, arquitetura, pintura e jardinagem ornamental), e do jogo das belas sensações (música e arte das cores). A poesia ocupa o lugar mais alto na hierarquia, seguida da música por um determinado critério. Se o critério for alterado, a música é rebaixada a último lugar na hierarquia. E dentre as artes figurativas a pintura é a mais elevada.

Encerrada esta etapa no desenvolvimento deste artigo doravante será exposta a divisão das belas artes segundo Hegel, no século XIX, para por fim ser apresentada uma análise comparativa entre ambas as propostas.

\section{Artes belas e artes particulares em Hegel}

Durante a marcha do espírito ao longo da história, o mesmo se manifestou concretamente no mundo por meio de obras de artes de diversas maneiras. As formas de manifestação da arte antiga, da arte medieval e da arte moderna são, por exemplo, manifestações do conteúdo espiritual que se materializou nas obras de artes ao longo do tempo histórico.

Contudo, Hegel observa que para se compreender este processo de diversas manifestações do espírito no tempo histórico é necessário ter como fio condutor o entendimento de que a arte se manifesta como determinadas concepções de mundo e também, de forma singular e concreta, como modos determinados de existência, isto é, como artes particulares. (HEGEL, 2001, p. 88) Dessa forma, a arte bela manifesta um conteúdo espiritual que expressa uma concepção de mundo, e faz isso por meio de uma determinada arte particular, efetivando concretamente o conteúdo espiritual que ela materializa.

Cabe observar que o critério elencado por Hegel para definir de que forma a arte bela apresenta concepções de mundo ao longo da história é a relação da "[...] Idéia com a sua configuração" (HEGEL, 2001, p. 91), isto é, de que forma a ideia apresenta seu conteúdo por meio da arte. Neste diapasão, segundo Hegel, há três formas: a arte simbólica, a arte clássica $e$ a arte romântica.

CARVALHO, Zilmara de Jesus Viana de; MELONIO, Danielton Campos. A divisão das belas artes: Kant e Hegel. Griot 
Na forma de arte simbólica (symbolische Kunstform), a mais antiga delas, a ideia ainda está confusa e indeterminada, ou determinada de forma não adequada, e é por esse motivo que o conteúdo espiritual não consegue se expor plenamente neste tipo de arte que expõe uma concepção de mundo que não se compreende a si mesmo ainda, não tem consciência de si. (HEGEL, 2001, p. 91)

Dito de outra forma, enquanto manifestação de um conteúdo que expressa ideias ainda confusas e indeterminadas,

[...] ela ainda não possui em si mesma aquela individualidade que o ideal requer; sua abstração e unilateralidade deixa a forma externamente deficiente e casual. Por isso, a primeira Forma de arte é ainda um mero procurar o ato de figuração [...] do que uma capacidade de exposição verdadeira. A Idéia ainda não encontrou a Forma em si mesma e permanece assim numa luta e aspiração por ela. (HEGEL, 2001, p. 91).

Por conseguinte, na expressão da arte simbólica, o conteúdo espiritual ainda não consegue plenamente se manifestar por meio da materialidade exposta pela obra de arte. Isto é, a obra de arte manifestada pela arte simbólica não concretiza a ideia, que permanece confusa, indeterminada e abstrata. A arte tenta expressar a ideia, mas as formas de manifestação artísticas concretas não permitem a plenitude de manifestação espiritual, por isso a arte simbólica é um mero tatear, uma busca, muitas vezes infrutífera, da manifestação do conteúdo da ideia através da arte.

Por sua vez, a forma de arte clássica (klassische Kunstform), diferentemente da anterior, consegue plenamente adequar o conteúdo da ideia com a forma de manifestação artística. Com efeito, "a Forma da arte clássica é a livre e adequada conformação [...] da Idéia na forma que pertence de modo peculiar à própria Idéia segundo seu conceito, com a qual, assim, ela pode entrar numa sintonia livre e completa." (HEGEL, 2001, p. 92)

Dessa maneira, é na arte clássica que, pela primeira vez, a ideia se manifesta de forma adequada em relação a sua figuração sensível, apresentando-se como conteúdo espiritual plenamente efetivado. (HEGEL, 2001) E a forma da arte clássica fazer isso é por meio da exposição da figura humana e não mais da natureza. A estátua grega antiga, por exemplo, é a figuração dos deuses que se materializaram na forma humana. A arte clássica é expressa na forma do humano, e por isso consegue efetivar de forma mais adequada o conteúdo espiritual, que é humano, algo que a arte simbólica não conseguiu fazer plenamente porque a figura humana ainda estava indeterminada e confusa como manifestação da ideia. (HEGEL, 2001)

Por fim, no que diz respeito a relação da ideia com a sua figuração imagética, a forma de arte romântica (romantische Kunstform) efetiva o conteúdo espiritual de outra maneira, a saber, ultrapassando o meramente externo e dirigindo sua exposição para a interioridade humana. Nesta forma de arte não importa tanto a expressão externa da obra (como a perfeição e harmonia dos traços da escultura grega, que representam de certa forma os deuses "aprisionados" no mármore), mas o conteúdo espiritual direcionado ao interior. É por isso que as pinturas medievais não se importam com a perfeição e com a proporcionalidade, porém com o conteúdo espiritual interior, sendo, se comparadas às esculturas gregas, consideradas feias e grotescas (ver figuras 1 e 2 abaixo).

Dito de outra maneira:

CARVALHO, Zilmara de Jesus Viana de; MELONIO, Danielton Campos. A divisão das belas artes: Kant e Hegel. Griot 
O lado da existência exterior é entregue à contingência e abandonado à aventura da fantasia, cuja arbitrariedade pode tanto espelhar o que está presente, tal como está presente, como também embaralhar e distorcer grotescamente as configurações do mundo exterior. Pois esta exterioridade não tem mais seu conceito e significado em si e junto a si mesma [...], como no clássico, mas no ânimo que tem sua aparição [...] em si mesmo e não na exterioridade e na Forma e realidade desta [...]. (HEGEL, 2001, p. 95)

Assim, na forma de arte romântica a espiritualidade se mostra como livre e concreta, dirigindo seu conteúdo para a interioridade, importando mais o conteúdo espiritual dirigido à interioridade do que a figuração imagética exterior da obra de arte, que pode até ser imperfeita e grotesca se comparada à exposição da forma de arte clássica. A forma de exposição exterior da obra de arte romântica não compromete a concretização do conteúdo espiritual da Ideia, uma vez que ela dirige esse conteúdo para o interior.

Com efeito, como o conteúdo desta forma de arte é essencialmente espiritual e dirigido à interioridade, a exposição externa da obra pode e deve se libertar dos limites da exterioridade material, manifestando-se em formas de artes mais livres quanto à sua exposição material. (HEGEL, 2001)

Depois da análise das formas de arte quanto à relação da ideia com a sua figuração imagética, expondo assim concepções de mundo nas formas das artes simbólicas, clássica e romântica, compreendendo que elas "[...] consistem na aspiração, na conquista e na ultrapassagem do ideal como verdadeira Idéia da beleza" (HEGEL, 2001, p. 96), respectivamente, a seguir serão analisadas as artes particulares propriamente ditas, segundo a classificação proposta por Hegel em seu Curso de Estética.

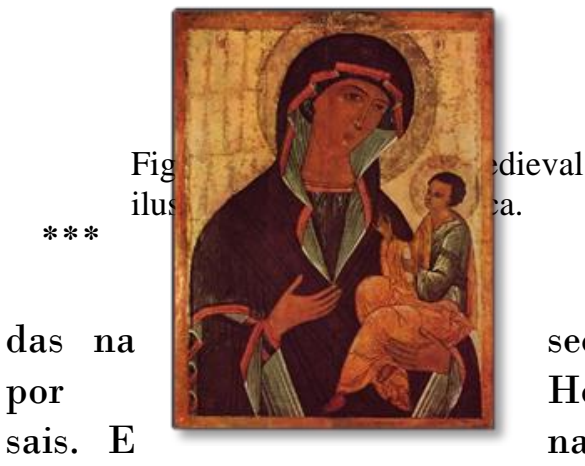

sais. E
As formas seção anterior são Hegel de formas na medida em que

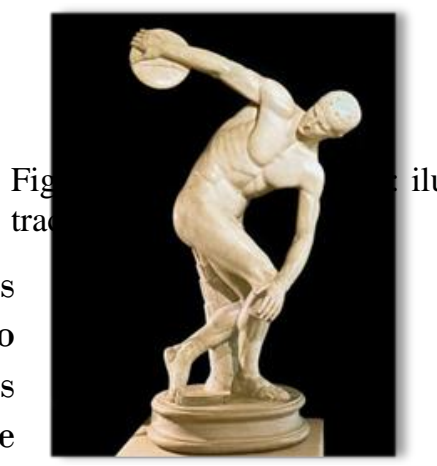
ilus-

de arte analisadenominadas de artes univerestas formas de exterior de

forma singular, particularizando e concretizando uma das formas de concepções de mundo em obras de arte propriamente ditas, passam a ser denominada de artes particulares, vinculando-se a um dos tipos de formas de artes universais.

Dito de outra forma,

[...] as artes particulares pertencem especificamente a uma das Formas de arte universais e constituem sua adequada efetividade artística exterior; por outro lado, apresentam a totalidade das Formas de arte segundo seu modo de configuração exterior (HEGEL, 2001, p. 96).

Assim, na perspectiva hegeliana, as artes particulares também expressam a totalidade, uma vez que as artes universais se manifestam nas particulares e estas também naquelas, numa relação dialética. Uma obra de arte carrega consigo a totalidade do espírito, e não é um mero objeto material, sem vida e sem conteúdo espiritual.

CARVALHO, Zilmara de Jesus Viana de; MELONIO, Danielton Campos. A divisão das belas artes: Kant e Hegel. Griot 
Ao classificar as artes particulares Hegel as apresenta como: arquitetura, escultura, pintura, música e poesia.

Sobre a bela arquitetura (schöne Architektur) é possível dizer que "[...] sua tarefa consiste em elaborar a natureza exterior inorgânica, para que ela se torne, como mundo exterior adequada à arte, apresentada ao espírito" (HEGEL, 2001, p. 97), isto é, a arquitetura transforma o mundo material exterior em algo próximo ao espírito, tornando-o assim arte arquitetônica. É dessa forma que por meio da arquitetura se abre pela primeira vez...

[...] o caminho para a efetividade adequada de Deus e trabalha a seu serviço com a natureza objetiva para tirá-la do matagal da finitude e da deformidade do acaso. E, assim, aplana o lugar para o Deus, dá Forma para o exterior que o rodeia e constrói seu templo como o espaço para a concentração e direcionamento para os objetos absolutos do espírito. Ela permite que uma envoltura se erga para o alto para a reunião dos fiéis - enquanto proteção conta a ameaça da tempestade, contra a chuva, o mau tempo e animais selvagens -, e manifesta aquele querer-se reunir, mesmo que de um modo exterior, mas ainda assim artístico (HEGEL, 2001, p. 98).

Com efeito, a arquitetura transforma o espaço construindo edifícios capazes de reunir os fiéis diante de um Deus, permitindo que eles estejam protegidos e abrigados enquanto se reúnem para este fim sagrado. Assim, a arquitetura, como forma artística, constrói templos e espaços não exatamente com fins imediatos imobiliários (uma casa para morar, por exemplo), mas produz artisticamente templos e espaços para o sagrado, tornando-se, por conseguinte, a particularização da Forma de arte simbólica. (HEGEL, 2001, p. 97-98)

Em seguida Hegel (2001, p. 98) apresenta a escultura (Skulptur) como outro tipo de arte particular. Por meio dela "[...] o interior espiritual para o qual a arquitetura apenas é capaz de apontar, habita a figura sensível e seu material exterior, e os dois lados se configuram um-no-outro de $t a l$ modo que nenhum deles prepondera [...]"(HEGEL, 2001, p. 98). Por meio da exposição da figura do corpo humano, mesmo que expressando a figura dos deuses, as obras de arte na forma de escultura (lembrando-se que Hegel aqui fez referências às esculturas gregas antigas e não qualquer tipo de escultura) efetivam o conteúdo espiritual por meio da obra. É assim que na escultura “[...] o interior e o espírito pela primeira vez aparecem em seu repouso eterno e autonomia essencial" (HEGEL, 2001, p. 99), e não como mero objeto espacialmente construído.

Por conseguinte, sendo uma particularização da arte clássica, a bela escultura manifesta no mundo exterior a conciliação entre interioridade (conteúdo espiritual) e exterioridade (manifestação material concreta da obra), efetivando pela primeira vez a ideia no mundo material, de forma adequada à sua exposição.

Depois, Hegel apresenta as três artes particulares que se vinculam à forma de arte universal romântica, a saber, a pintura, música e poesia.

A primeira delas, a pintura (Malerei), utiliza "[...] como material para seu conteúdo e sua configuração a visibilidade enquanto tal, na medida em que esta se particulariza imediatamente nela mesma, isto é, se determinada como cor." (HEGEL, 2001, p. 100). Com efeito, mesmo se apresentando visivelmente, como ocorre com a arquitetura e a escultura, a pintura se caracteriza pela cor, libertando-se da materialidade meramente espacial pesada da arquitetura e da escultura. (HEGEL, 2001, p. 100)

Assim, tanto numa pintura feita em uma tela medindo $77 \mathrm{~cm}$ x $53 \mathrm{~cm}$ (como é o caso da Monalisa del Giocondo), quanto noutra pintura realizada no teto de uma igreja (como

CARVALHO, Zilmara de Jesus Viana de; MELONIO, Danielton Campos. A divisão das belas artes: Kant e Hegel. Griot 
por exemplo o Teto da Capela Sistina), medindo $40 \mathrm{~m}$ x $14 \mathrm{~m}$, as dimensões espaciais não têm tanta importância. $O$ mais fundamental aqui na pintura são os desenhos e as cores, que manifestam um conteúdo espiritual que ultrapassa a materialidade exterior da obra, tornado, desse modo, a pintura livre da mera espacialidade pesada das artes particulares anteriores.

A segunda forma de arte particular desdobrada da forma de arte romântica é a música (Musik). Embora se manifeste por meio de um material ainda sensível, a saber, os sons, "o seu material progride para uma subjetividade e particularização ainda mais profundos" (HEGEL, 2001, p. 101), isto é, a materialidade exterior na música é muito menos necessária do que nas artes particulares supracitadas, tornando-se, portanto, mais interior que exterior.

O caráter menos material da música em relação à arquitetura, à escultura e à pintura se dá porque ela se manifesta como som (Ton) e não como objeto material. E o som é uma manifestação no tempo e não no espaço, pois "na medida em que o som desprende o ideal como que de seu confinamento na materialidade" isto permite que os sons produzidos pela música ressoem no ânimo, apresentando o material espiritual por meio da obra musical. (HEGEL, 2001, p. 101)

Na classificação das artes particulares apresentada por Hegel, a última arte particular romântica é a poesia (Poesie), e sua peculiaridade “característica reside na potência com que submete ao espírito e as suas representações o elemento sensível, do qual a música e a pintura já haviam começado a libertar a arte." (HEGEL, 2001, p. 101) Na poesia, o som, que é o material exterior de sua manifestação, deixa de ser uma simples sensação sonora para se tornar palavra, quem tem por objetivo:

[...] designar representações e pensamentos, na medida em que o ponto em si mesmo negativa, para a qual a música se dirigia, agora se apresenta como um ponto completamente concreto, como ponto do espírito, como o indivíduo autoconsciente que a partir de si mesmo une o espaço infinito da representação ao tempo do som. (HEGEL, 2001, p. 101)

Com efeito, o conteúdo manifesto pela poesia é totalmente espiritual e o seu único elemento "material", o som, não aprisiona a poesia na materialidade pesada espacial. As palavras poéticas são direcionadas exclusivamente à interioridade e seu conteúdo é espiritual, assim, efetivo. Na poesia, o espírito é totalmente livre da materialidade artística, capaz de manifestar obras de arte totalmente espirituais.

Dessa forma, as artes particulares românticas (começando pela pintura, passando pela música até a poesia) foram libertando paulatinamente o espírito da exposição material exterior, permitindo-o manifestar o seu conteúdo espiritual sem a obrigatoriedade da exposição exterior. Na arquitetura e na escultura a Ideia não conseguia ainda se manifestar livremente, estando condicionada à materialidade espacial. A partir da pintura, passando pela música até a poesia o espírito foi se libertando cada vez mais da materialidade exterior e se manifestado como interioridade, manifestando de forma mais efetiva o conteúdo espiritual da Ideia.

Pelo que foi exposto é possível perceber que a hierarquia das artes particulares propostas por Hegel segue o critério da arte mais vinculada à materialidade até aquela mais liberta desta exterioridade, ou seja, da arte menos espiritual à mais espiritual.

Nesse sentido, a poesia ocupa o lugar mais alto nesta escala pois "[...] é adequada a todas as Formas do belo e se estende sobre todas elas, porque seu autêntico elemento é a 
bela fantasia, e a fantasia é necessária para toda produção da beleza, seja qual for a Forma a que pertença." (HEGEL, 2001, p. 103) Dessa forma, a poesia permite desenvolver a bela fantasia, condição para qualquer expressão artística, seja qual for a expressão particular que se pretenda utilizar.

Em segundo lugar, vem a música, depois a pintura, a escultura e, por fim, a arquitetura na hierarquia das artes belas seguindo o critério hegeliano. Assim, esta é a classificação hierárquica das artes belas proposta por Hegel.

Portanto, pelo exposto, foi possível apresentar a divisão das artes belas segundo Hegel em seu Curso de Estética. Primeiramente, foi possível perceber que a arte é uma manifestação livre do espírito humano, e que por isso se diferencia do belo natural. Em seguida, foram apresentadas as formas de arte simbólica, clássica e romântica, permitindo-nos compreender de que maneira o espírito manifesta concepções de mundo através da arte ao longo do tempo histórico, primeiro como uma tentativa (simbólico), depois se efetivando na materialidade espacial (clássico) e posteriormente ultrapassando a materialidade espacial em direção a interioridade espiritual (arte romântica). Por fim, foram expostas as artes particulares e a sua hierarquia, permitindo-nos perceber que a poesia ocupa o lugar mais alto na escala, pois é a mais espiritual e, por conseguinte, menos material das artes belas. Dessa maneira, foi exposta a divisão das artes belas segundo Hegel.

\section{Afinidades e diferenças entre Kant e Hegel na divisão das belas artes}

Depois de ter exposto a divisão das artes belas propostas por Kant na Crítica da Faculdade do Juízo e de Hegel no Cursos de Estética cabe nos agora questionar: Quais as afinidades e distanciamentos entre a divisão das belas artes apresentadas por Kant e Hegel?

No que diz respeito às diferenças entre Kant e Hegel neste tema destacam-se as seguintes: (1) Kant defende que não se pode fazer uma abordagem científica e nem que há uma ciência da arte, enquanto Hegel defende que há uma ciência do belo, isto é, uma Filosofia da bela arte. (2) Para Kant a autêntica obra de arte tem que parecer como se fosse obra da natureza, e para Hegel só há belo artístico como objeto para a ciência do belo, e o belo natural não é considerado; assim, Kant prioriza o belo natural, enquanto Hegel o belo artístico. (3) Segundo Kant, a arte bela é produzida pelo gênio, que tem por tarefa fazer parecer a arte como se fosse obra da natureza; Hegel, por sua vez, afirma que a arte é manifestação do conteúdo espiritual, não focando em sua argumentação na figura do artista que produz a obra de arte, mas investiga como ele consegue manifestar o conteúdo espiritual por meio desta obra, concretizando a ideia e manifestando-a na história. (4) O critério utilizado por Kant para dividir as artes belas são os modos que os humanos utilizam para se comunicar entre si, isto é, por meio da fala, do gesto e do som; Hegel, por seu turno, adota outro critério, afirmando que a divisão entre elas se dá devido à forma como conseguem manifestar adequadamente o conteúdo espiritual por meio da obra exterior, da arte menos espiritual e mais exterior, para a mais espiritual e mais interior. (5) Kant classifica, de forma geral, as belas artes em artes elocutivas (eloquência e poesia), figurativas (plásticas: escultura e arquitetura e pictórica: pintura e jardinagem ornamental) e jogo das belas sensações (música e arte das cores); Hegel divide-as em formas de artes universal (simbólica, clássica e romântica) e artes particulares (arquitetura, escultura, pintura, música e poesia). (6) Diferentemente de Hegel, Kant apresenta a eloquência, a jardinagem ornamental e a arte das cores como belas artes, que não são mencionadas por Hegel.

CARVALHO, Zilmara de Jesus Viana de; MELONIO, Danielton Campos. A divisão das belas artes: Kant e Hegel. Griot 
Assim, devido à diferença em seus sistemas filosóficos, é possível perceber que Kant e Hegel discordam em diversos aspectos na divisão das belas artes, em especial na possibilidade de uma ciência da arte e no enfoque que dão ao belo, defendendo o primeiro, o belo natural, enquanto o último defende o belo artístico. Ademais, a diferença nos critérios que utilizam para dividir as artes merece destaque também.

No que tange às semelhanças, os pontos de possíveis interseções são estes: (1) A arte é produção humana livre. (2) Kant e Hegel destacam a arquitetura, escultura, pintura, música e poesia como belas artes. (3) Para Kant e Hegel a bela arquitetura tem em comum o caráter de produzir espaços para a reunião das pessoas em torno do sagrado. (4) Tanto Kant quanto Hegel destacam o caráter não meramente sensorial da música, afirmando que ela deve ser percebida estruturalmente, com seu caráter matemático (tempo, divisão dos compassos, etc.), e não apenas como sons que são percebidas na pura sensação. (5) Na hierarquia das belas artes, Kant coloca a poesia no topo, afirmando que é a mais livre das artes; em segundo lugar (usando o critério da importância do movimento do ânimo) está a música, e em terceiro a pintura; porém se utilizarmos o critério do alargamento da cultura Kant coloca a música em último lugar na escala, declarando que lhe falta certa urbanidade. (6) Hegel, por sua vez, também destaca a poesia como a mais alta das belas artes, seguida da música, pintura, escultura e por último a arquitetura, utilizando como critério da arte mais livre da exterioridade (a poesia) para a mais presa a ela (a arquitetura).

Por conseguinte, entre os pontos em comum, apesar da distinção entre os sistemas filosóficos de Kant e Hegel, destaca-se a importância e o valor que dão à bela arte da poesia, pois ambos a colocaram no topo da hierarquia das belas artes. Ressaltam o seu caráter livre e desmaterializado, mais afeito à razão e ao espírito.

Portanto, apesar das diferenças entre as concepções de arte bela, sua divisão e hierarquia, Kant e Hegel ressaltam a necessidade de se realizar uma análise filosófica sobre a arte, salientando seus elementos estruturais e necessários. E a partir das conclusões aqui apresentadas cabe aprofundar em outra investigação o papel da poesia como forma de acesso ao mundo espiritual e ao suprassensível, abrindo caminho para pesquisas ulteriores sobre o tema. 


\section{Referências}

ALLISON, Henry E. Kant's Theory of Taste: a Reading of the Critique of Aesthetic Judgment. New York: Cambridge University Press, 2001. E-book.

CASSISER, E. (1997). Filosofia do Iluminismo. Trad. Álvaro Cabral 3. ed. Campinas, SP: Editora da UNICAMP.

GONÇALVES, M. (2004). A idéia da corporalidade na estética de Hegel. In: MORAES, A. O. Razão nos trópicos: festschrift em homenagem a Paulo Meneses no seu $80^{\circ}$ aniversário. Recife: FASA.

$109, \mathrm{Jun} / 2004$, p. 46-56. (2004). A morte e a vida da arte. KRITERION, Belo Horizonte, $\mathbf{n}^{\circ}$

. (2005). Uma concepção dialética da arte a partir da gênese do conceito de trabalho na fenomenologia do espírito de Hegel. KRITERION, Belo Horizonte, $\mathrm{n}^{\circ} 112$, Dez/2005, p. 260-272.

HEGEL, G. W F. (2001). Cursos de estética. Vol. I. Tradução de Marco Aurélio Werle. São Paulo: EDUSP.

(1995). Enciclopédia das ciências filosóficas em compêndio: 1830. Texto completo, com os adendos orais, traduzido por Paulo Meneses, com a colaboração de José Machado. São Paulo: Loyola.

HUGHES, F. (2014). "Um potencial político no juízo estético reflexionante: Kant, Hannah Arendt e "Pequena esparta, de Ian Hamilton Finlay". Tradução de Giorgia Cecchinato. In: Gosto, interpretação e crítica, Vol.1, ed. por Verlaine Freitas, Rodrigo Duarte, Giorgia Cecchinato, Cíntia Vieira da Silva, Belo Horizonte, Relicário.

KANT. I. (1957). Kritik der Urteilsckaft und naturphilosophische Schriften 2. In: KANT. Werke in Zwölf Bänden. Bänden X. Frankfurt, Germany: Suhrkamp Verlag. (1995). Crítica da faculdade do juízo. 2. ed. Tradução de Valério Rohden e António Marques. Rio de Janeiro: Forense Universitária.

(2017). Crítica da Faculdade de Julgar. Tradução de Fernando Costa Mattos. Petrópolis, RJ: Vozes; Bragança Paulista, SP: Editora Universitária São Francisco. E-book Kindle.

WOOD, Allen W. (2008). Kant. Tradução de Delamar José Volpato Dutra. Porto Alegre: Artmed.

Contribuição dos autores:

Danielton Campos Melonio e Zilmara de Jesus Viana de Carvalho redigiram a primeira secção do artigo, que aborda a divisão das belas-artes proposta por Immanuel Kant na Crítica da Faculdade do Juízo. Danielton Campos Melonio redigiu a segunda seção sobre a divisão das belas-artes exposta por Hegel nos Cursos de Estética. Danielton Campos Melonio e Zilmara de Jesus Viana de Carvalho redigiram a última seção do artigo, que analisa as afinidades e diferenças entre a divisão das belas-artes propostas por Kant e Hegel. Zilmara de Jesus Viana de Carvalho fez a revisão do artigo e ambos os autores aprovaram a sua versão final.

Autor(a) para correspondência: Danielton Campos Melonio, Universidade Federal do Maranhão, Av. dos Portugueses, 1966 - Vila Bacanga, CEP 65080-805, São Luís - MA, Brasil. dasein.da@gmail.com 